\title{
Initiation of renal replacement therapy in patients with septic acute kidney injury: right timing or right patient?
}

\author{
Saber Davide Barbar ${ }^{1,2}$, Auguste Dargent ${ }^{3,4}$, Jean-Pierre Quenot ${ }^{3,4,5,6}$ \\ ${ }^{1}$ Service des Réanimations, CHU de Nîmes, France; ${ }^{2}$ Université de Montpellier, Faculté de Médecine de Montpellier-Nîmes, EA 2992, Nîmes, \\ France; ${ }^{3}$ Service de Médecine Intensive-Réanimation, CHU Dijon Bourgogne, France; ${ }^{4}$ Université Bourgogne-Franche-Comté, UMR1231 Lipides, \\ Nutrition, Cancer, équipe Lipness, Dijon, France; ${ }^{5}$ LipSTIC LabEx, Fondation de coopération scientifique Bourgogne-Franche-Comté, Dijon, \\ France; ${ }^{6}$ INSERM, CIC 1432, Module Epidémiologie Clinique, Dijon, France \\ Correspondence to: Jean-Pierre Quenot. Department of Intensive Care, François Mitterrand University Hospital, 14 rue Paul Gaffarel, 21079 Dijon, \\ France. Email: jean-pierre.quenot@chu-dijon.fr. \\ Provenance: This is an invited article commissioned by the Section Editor Dr. Wei Liu (Department of Nephrology, Anqing Municipal Hospital, The \\ Affiliated Anqing Hospital of Anhui Medical University, Anqing, China). \\ Response to: Uhel F, Peters-Sengers H, van der Poll T. Initiation of renal replacement therapy in patients with sepsis: more to it than meets the eye. \\ Ann Transl Med 2018;6:S130. \\ Zhang Z. No "optimal timing" of renal-replacement therapy in critically ill patients with acute kidney injury. Ann Transl Med $2018 ; 6: S 112$.
}

Submitted Aug 28, 2019. Accepted for publication Sep 12, 2019.

doi: $10.21037 /$ atm.2019.09.78

View this article at: http://dx.doi.org/10.21037/atm.2019.09.78

We thank Dr. Zhang and Uhel et al. for their interest in our study IDEAL-ICU (1) and appreciate their pertinent comments $(2,3)$. Indeed, from two different points of view, they draw an accurate and synthetic overview of the state of knowledge on the timing of renal replacement therapy (RRT) for acute kidney injury (AKI) in intensive care unit (ICU) patients. However, we only partially agree with their conclusions.

Dr. Zhang (3) affirms that "an attempt to protocolize an "optimal timing" of RRT in critically ill patients with AKI based on pre-defined thresholds may be imprecise and impractical". When we designed the IDEAL-ICU study, our goal was to demonstrate that early initiation of RRT could reduce mortality in patients with severe AKI associated with septic shock. In our study, we failed to prove that early initiation of RRT yields such a benefit. However, two strong messages emerged from our results.

The first is that the values of serum creatinine and urine output (which are components of the RIFLE and KDIGO criteria) should not be used to decide on the initiation of RRT. Experts in the field will attest to the fact that these classifications were not initially designed for the purposes of identifying the need for RRT, and the latest version of the Surviving Sepsis Campaign (4) suggests "against the use of RRT in patients with sepsis and acute kidney injury for increase in creatinine or oliguria without other definitive indications for dialysis". Yet, just a few years before the publication of our study, a large majority of intensivists and nephrologists used serum creatinine and urine output to decide on when to initiate RRT. In two surveys, one European and one north American, about $75 \%$ of them were likely to initiate early dialysis; and fixed values of urea/creatinine or urine output $<0.5 \mathrm{~mL} / \mathrm{kg} / \mathrm{h}$ for 6 hours were chosen as criteria to initiate RRT $(5,6)$. Although protocolizing the optimal timing of RRT for all patients may be imprecise, in the era of personalized medicine, it is all the more important to give clinicians reliable information about which tools they should or should not use to make the best choice for each patient.

The second strong message to come out of the IDEALICU study is that about $30 \%$ of patients with severe AKI associated with septic shock will never actually need RRT, thanks to spontaneous recovery of renal function, which occurs within as little as 48 hours. The pathophysiology of septic AKI, which alone accounts for more than half of AKI in the ICU, is not completely understood, but it is clear that in the early phases at least, there is no acute tubular necrosis and only intracellular and metabolicand therefore quickly reversible-modifications are 
observed (7). While we await targeted drug therapies capable of blocking and reversing septic AKI (8), for the moment, for most septic shock patients, early RRT is not the answer to severe AKI. It is unacceptable to expose $30 \%$ of patients to the potential risks of an extracorporeal support technique if they do not actually need it, not to mention the savings to be yielded in terms of costs, time, and organization of the ICU department. Moreover, the 48-hour delay is exactly the median half-life of vasopressor support (9), so even patients who actually need RRT are more hemodynamically stable and can better tolerate it.

Uhel et al.'s interpretation (2) of our study is "that both early and delayed approaches could bring variable levels of benefit to specific subgroups of patients." Indeed, in our study, $17 \%$ of patients developed critical criteria for emergency RRT, with higher mortality. We agree that there is a compelling need for better and earlier identification of more severe patients, using clinical or biological profiles, with a view to optimizing their treatment. Nevertheless, our results preclude any inference that those patients are more likely to benefit from an earlier RRT approach.

The challenge is now to tailor future trials to investigate the optimal medical management of patients with critical criteria for emergency RRT. The results of the BICAR-ICU study (10) seem to suggest that in case of severe metabolic acidosis associated with severe AKI, the optimization of medical treatment can avoid RRT, thus reducing mortality. It is less clear which is the better approach in case of hyperkalemia and fluid overload.

It should be kept in mind that the interpretation of our data refers to a septic AKI population only.

\section{Acknowledgments}

None.

\section{Footnote}

Conflicts of Interest: The authors have no conflicts of interest to declare.

Ethical Statement: The authors are accountable for all aspects of the work in ensuring that questions related to the accuracy or integrity of any part of the work are appropriately investigated and resolved.

\section{References}

1. Barbar SD, Clere-Jehl R, Bourredjem A, et al. Timing of Renal-Replacement Therapy in Patients with Acute Kidney Injury and Sepsis. N Engl J Med 2018;379:1431-42.

2. Uhel F, Peters-Sengers H, van der Poll T. Initiation of renal replacement therapy in patients with sepsis: more to it than meets the eye. Ann Transl Med 2018;6:S130.

3. Zhang Z. No "optimal timing" of renal-replacement therapy in critically ill patients with acute kidney injury. Ann Transl Med 2018;6:S112.

4. Rhodes A, Evans LE, Alhazzani W, et al. Surviving Sepsis Campaign: International Guidelines for Management of Sepsis and Septic Shock: 2016. Intensive Care Med 2017;43:304-77.

5. Legrand M, Darmon M, Joannidis M, et al. Management of renal replacement therapy in ICU patients: an international survey. Intensive Care Med 2013;39:101-8.

6. Thakar CV, Rousseau J, Leonard AC. Timing of dialysis initiation in AKI in ICU: international survey. Crit Care 2012;16:R237.

7. Dellepiane S, Marengo M, Cantaluppi V. Detrimental cross-talk between sepsis and acute kidney injury: new pathogenic mechanisms, early biomarkers and targeted therapies. Crit Care 2016;20:61.

8. Pickkers P, Mehta RL, Murray PT, et al. Effect of Human Recombinant Alkaline Phosphatase on 7-Day Creatinine Clearance in Patients With Sepsis-Associated Acute Kidney Injury: A Randomized Clinical Trial. JAMA 2018;320:1998-2009.

9. Quenot JP, Binquet C, Kara F, et al. The epidemiology of septic shock in French intensive care units: the prospective multicenter cohort EPISS study. Crit Care 2013;17:R65.

10. Jaber S, Paugam C, Futier E, et al. Sodium bicarbonate therapy for patients with severe metabolic acidaemia in the intensive care unit (BICAR-ICU): a multicentre, open-label, randomised controlled, phase 3 trial. Lancet 2018;392:31-40.

Cite this article as: Barbar SD, Dargent A, Quenot JP. Initiation of renal replacement therapy in patients with septic acute kidney injury: right timing or right patient?. Ann Transl Med 2019;7(20):598. doi: 10.21037/atm.2019.09.78 